\title{
Influence of Rare Earth on Dynamic Recrystallization Behavior of As-Cast 30Mn Steel
}

\author{
Honghong Yan, ${ }^{1}$ Yong $\mathrm{Hu} \mathbb{D D}^{2}$ and Dawen $\mathrm{Zhao}^{2}$ \\ ${ }^{1}$ School of Mechanical Engineering, Taiyuan University of Science and Technology, Taiyuan, Shanxi 030024, China \\ ${ }^{2}$ School of Materials Science and Engineering, Taiyuan University of Science and Technology, Taiyuan, Shanxi 030024, China \\ Correspondence should be addressed to Yong Hu; hytyust@163.com
}

Received 19 October 2017; Revised 1 December 2017; Accepted 4 December 2017; Published 14 February 2018

Academic Editor: Ivan Gutierrez-Urrutia

Copyright $($ C) 2018 Honghong Yan et al. This is an open access article distributed under the Creative Commons Attribution License, which permits unrestricted use, distribution, and reproduction in any medium, provided the original work is properly cited.

Based on casting-rolling compound forming process, the effect of rare earth on dynamic recrystallization (DRX) of as-cast 30Mn steel was investigated by the single-pass hot compression tests performed using a Gleeble-3500 thermomechanical simulator, and the deformation temperature range was $950^{\circ} \mathrm{C}-1150^{\circ} \mathrm{C}$ and strain rate range was $0.1-1 \mathrm{~s}^{-1}$. With the assistance of the process parameters, constitutive equations were used to obtain the activation energy and hot working equation. The dynamic recrystallization kinetics models of the tested steel were constructed. The results show that rare earth ferrosilicon alloy addition $(0.2 \%$, mass fraction) can delay the onset of DRX significantly and refine the hot deformation microstructures. All of the results indicate that the addition of rare earth into as-cast $30 \mathrm{Mn}$ steel is helpful to prepare excellent cast slab for the casting-rolling compound forming technology.

\section{Introduction}

Bearing ring and wind power flange are very broad important infrastructure components in the equipment manufacturing industry. The traditional ring manufacturing technique exhibits characteristics of long process flow, multiple heating, severe waste of materials, and environmental pollution, and so on. Therefore, a new process, named "casting-rolling compound forming process," was proposed. In this process, cast slab is used to roll into a ring directly $[1,2]$. During the casting-rolling compound forming process, the hot working character of the cast slab directly affects the final quality of the ring. At present, more and more researchers focus on the hot deformation behavior of the as-forged or rolled steels. However, there are few reports about hot deformation behavior of the ascast steels.

During the hot deformation of steels, the major softening mechanism is dynamic recrystallization (DRX) for the austenite steels with low stacking fault energy [3]. DRX plays an important role in the control of microstructure and mechanical properties of steels during hot working [4].
Therefore, the study on dynamic recrystallization of steels during the hot deformation is very necessary.

The final hot deformed microstructure is influenced by many factors, for example, casting blank chemical composition, grain size before deformation, deformation temperature, strain rate, and so on [5]. Grain refinement is an effective way to improve the strength and toughness of alloy steels simultaneously. Generally, lower terminal rolling temperature is helpful to obtain finer grains. However, it is impossible to deform at a very low terminal rolling temperature during the mass production. Usually, the appropriate amount of microalloy elements addition is an effective means to inhibit austenite grain coarsening during heating and hot deformation. Rare earth is regarded as an important kind of microalloying elements, which can affect recrystallization behavior of alloy steel, for example, increasing the recrystallization temperature and refining crystal grains after hot deformation [6].

$30 \mathrm{Mn}$ steel is an appropriate material for many engineering applications because of high strength and good ductility. This article focuses on the effect of rare earth addition on the hot deformation behavior of as-cast 30Mn steel. 
These results will provide theoretical basis for a reasonable design of hot working process of as-cast 30Mn steel and offer references for preparation of higher quality of cast slab, which would be used in the casting-rolling compound forming process.

\section{Materials and Methods}

The chemical composition of the $30 \mathrm{Mn}$ steel used in this study is as follows (mass percent, \%): C 0.28, Si 0.48, Mn 1.4, $\mathrm{S} 0.019, \mathrm{P} 0.027$, and balance iron. One type of as-cast $30 \mathrm{Mn}$ steel was added $0.2 \%$ rare earth ferrosilicon alloy (containing $28.3 \%$ of rare earth) and another was not added in this study. They were marked by \# 1 (without rare earth addition) and \#2 (with rare earth addition), respectively. The samples with a height of $12 \mathrm{~mm}$ and a diameter of $8 \mathrm{~mm}$ for hot deformation were prepared. In order to reduce the probability of inhomogeneous compression, special anvils were employed. Both ends of the specimen were covered with tantalum foils to prevent adhesion between the specimen and anvils [7]. The specimens were austenitized at $1200^{\circ} \mathrm{C}$ for $5 \mathrm{~min}$ and then cooled with the rate of $5^{\circ} \mathrm{C} / \mathrm{s}$ to deformation temperature and held for $1 \mathrm{~min}$ before compression. Singlepass compression tests were carried out at the temperature range from $950^{\circ} \mathrm{C}$ to $1150^{\circ} \mathrm{C}$ with an interval of $50^{\circ} \mathrm{C}$ and strain rates of $0.1,0.5$, and $1 \mathrm{~s}^{-1}$ under a true strain of about 0.9 . In order to keep the morphology of high temperature austenite structure, the specimens were quenched into water immediately after compression. The quenched samples were sliced along the axial section. The sections were polished and etched with supersaturated picric acid to study the microstructure. The austenite recrystallization grain size was measured by the "linear intercept" using an optical microscope.

\section{Results and Discussion}

3.1. Flow Stress Curves. The true stress-true strain curves of \#1 and \#2 samples under different deformation conditions are shown in Figures 1 and 2. It can be seen that at the early stage of deformation, the stress increase is proportional to the strain, which leads to an increase of dislocation density and distortion degree in the matrix of \#1 and \#2 samples. This process is considered as the work-hardening process. At the second stage, the work-hardening effect is reduced owing to dislocation slipping, rearranging, or eliminating. At this moment, the strain hardening rate is equal to zero and the stress reaches the peak [8]. From Figures 1 and 2, it can be found that stress values and the peak stresses of \#2 sample are systematically larger than that of \#1 sample. These results indicate that rare earth elements could induce some hardening during dynamic recovery. Cabrera et al. [9] related that rare earth elements must be precipitated in MnS inclusions, or in the form of oxide or oxysulfide particles, or alternatively dissolved in the bulk material. They reasoned that rare earth played a major significant role on hardening mechanisms rather than on softening during dynamic recovery.
In addition, higher temperature or lower strain rate results in lower stress, as shown in Figures 1 and 2. That is to say, DRX is easier to occur at higher temperature or lower strain rate. The phenomenon can be attributed to the fact that higher temperature can enhance the thermal activation of atoms, decrease the atomic critical shear stress, and increase the softening degree of the material. Likewise, the lower strain rate can lead to a decrease of dislocation density in grain boundaries, thus resulting in an increase of lowstress concentration regions $[10,11]$.

Figure 3 shows the true stress-true strain curves of \#1 and \#2 samples at $1050^{\circ} \mathrm{C}$ and $0.1-1 \mathrm{~s}^{-1}$. Under the same deformation conditions, it is obviously found that the flow stress of \#2 sample is higher than that of \#1 sample under different strain rates. And at different temperatures, more deformation is needed for the onset of dynamic recrystallization in \#2 sample. It is concluded that the occurrence of the dynamic recrystallization of \#2 sample is more hysteretic than that of \#1 sample. These results indicate that rare earth elements addition in $30 \mathrm{Mn}$ steel can significantly inhibit the occurrence of dynamic recrystallization. Analogous result was reported [9] that rare earth metals were able to delay the onset of dynamic recrystallization through a solute drag effect.

It is well known that the grain boundary migration is usually affected by the grain boundary segregation of solute atoms significantly. Mclean and Northcott [12] indicated, regardless of whether the solution element is distributed in the body of grains or at the grain boundaries, that the driving force of grain boundary segregation is dependent on the distortion energy difference. The greater the solute and solvent atomic radius difference, the greater the distortion energy difference is.

For iron-based alloys, the rare earth atoms mostly tend to segregate at grain boundaries of austenite or interface between phases due to a much larger atomic radius [13]. Generally, carbon atoms in these regions tend to have a strong ability to diffuse. However, as rare earth elements segregate at the grain boundaries, the diffusion of carbon atoms is weakened. The literates also have indicated that the mobility of grain boundaries is limited by the rare earth dragging effect due to the enrichment of rare earth at the grain boundaries $[14,15]$.

Dynamic recrystallization is nucleation and grain growth process, which is controlled by the grain boundary migration. So the progress of dynamic recrystallization is impeded as a result of rare earth addition.

3.2. Deformation Activation Energy and Hot Working Equation. When the chemical composition has been given, the relationship between flow stress and the deformation condition can be described by the classical hyperbolic sine function $[16,17]$ :

$$
\dot{\varepsilon}=A \cdot\left[\sinh (\alpha \sigma)^{n}\right] \exp \left[\frac{-Q}{(\mathrm{RT})}\right] .
$$

To obtain parameter $\alpha$, the following formulas are also used: 


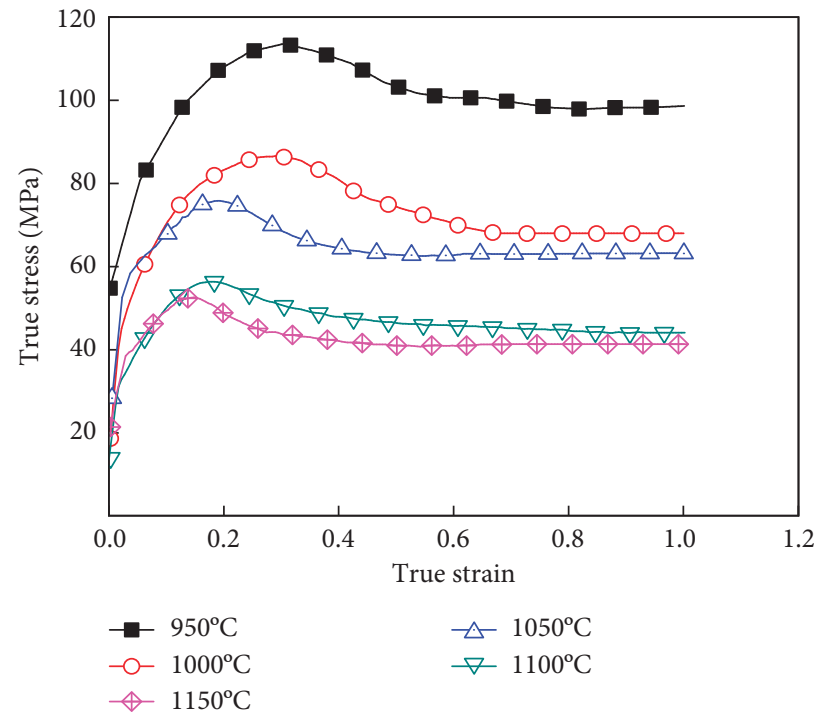

(a)

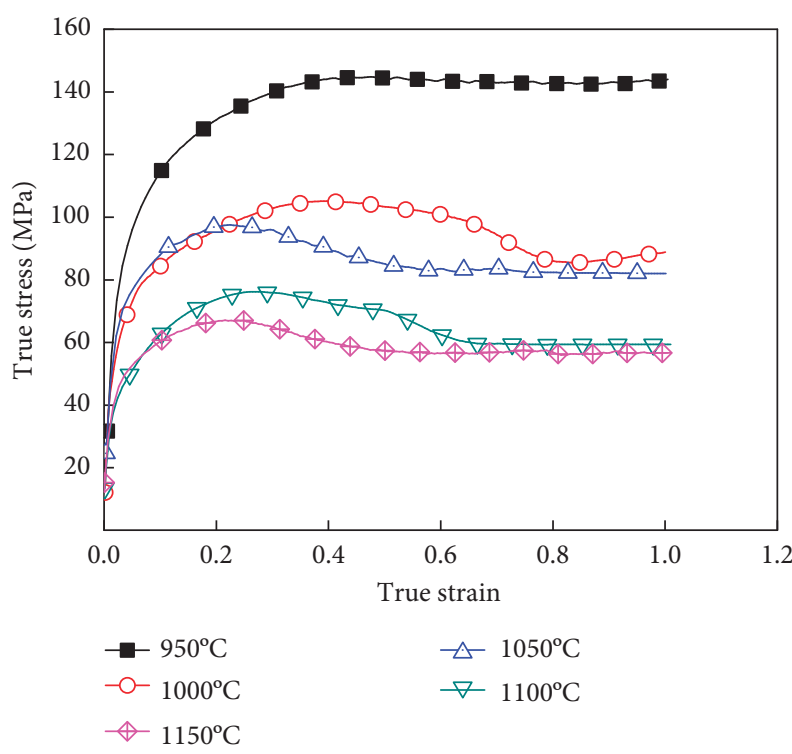

(b)

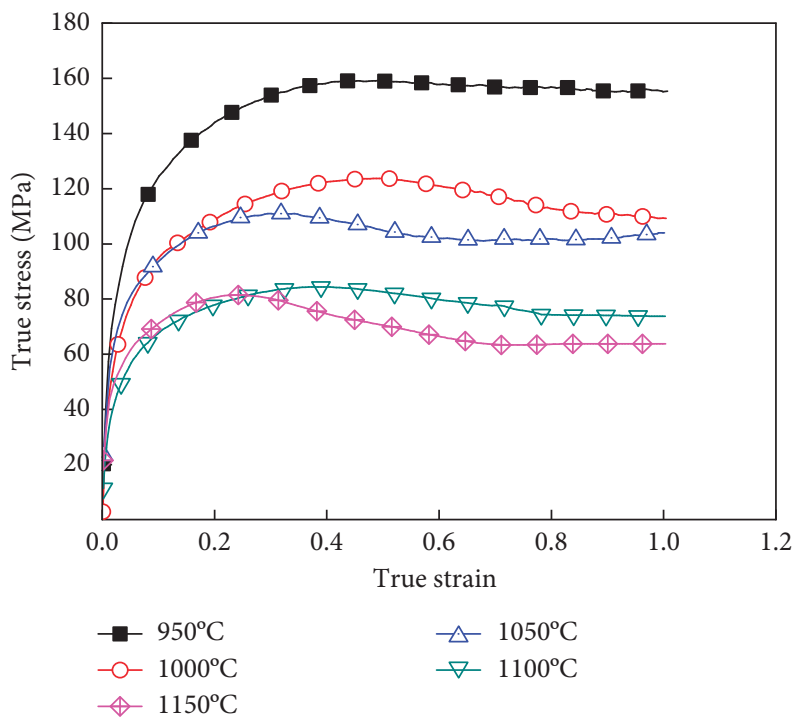

(c)

Figure 1: True stress-true strain curves of \#1 sample under different temperatures and strain rates. (a) $0.1 \mathrm{~s}^{-1}$; (b) $0.5 \mathrm{~s}^{-1}$; (c) $1 \mathrm{~s}^{-1}$.

for low stress $(\alpha \sigma<0.8)$,

$$
\dot{\varepsilon}=A_{1} \cdot \sigma^{n^{\prime}} \exp \left[\frac{-Q}{(\mathrm{RT})}\right]
$$

for high stress $(\alpha \sigma>1.2)$,

$$
\dot{\varepsilon}=A_{2} \cdot \exp (\beta \sigma) \exp \left[\frac{-Q}{(\mathrm{RT})}\right]
$$

where $\dot{\varepsilon}$ is the strain rate, $R$ is the universal gas constant, $T$ is the absolute temperature, $Q$ is the hot deformation activation energy, and $\sigma$ is the stress; in this paper, the peak stress is taken, where $A, A_{1}, A_{2}, n$, and $n^{\prime}$ are constants of the material, and $\alpha, \beta$, and $n^{\prime}$ are related by $\alpha=\beta / n^{\prime}$.

The Zener-Hollomon parameter or $Z$ parameter is widely used to characterize the combined effects of deformation temperature and strain rate on the deformation process. It can be expressed as follows [18]:

$$
Z=\dot{\varepsilon} \exp \left(\frac{\mathrm{Q}}{\mathrm{RT}}\right)
$$

Taking natural logarithms of both sides of formulas (2) and (3), respectively, the results are as follows: 


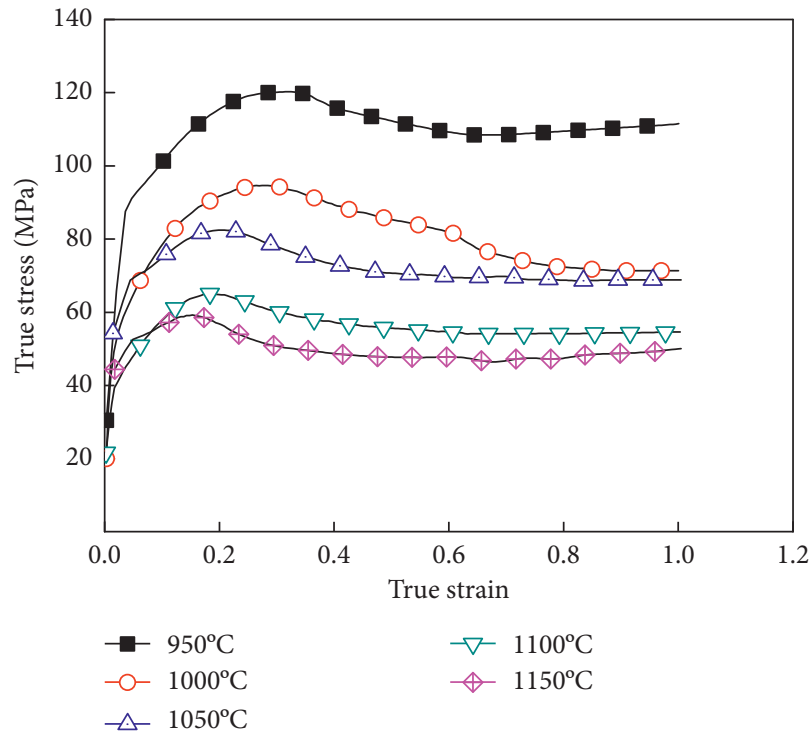

(a)

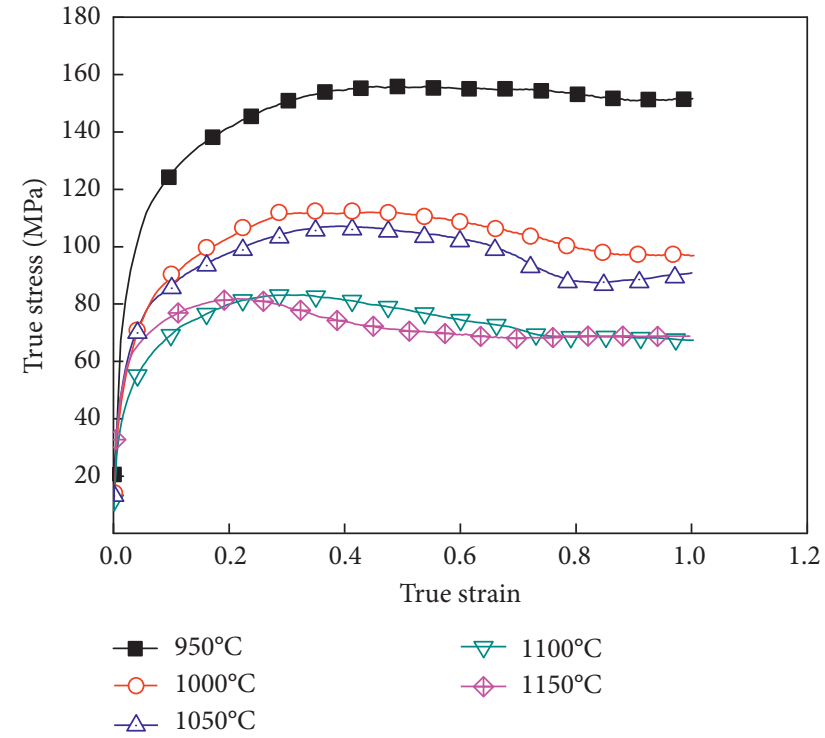

(b)

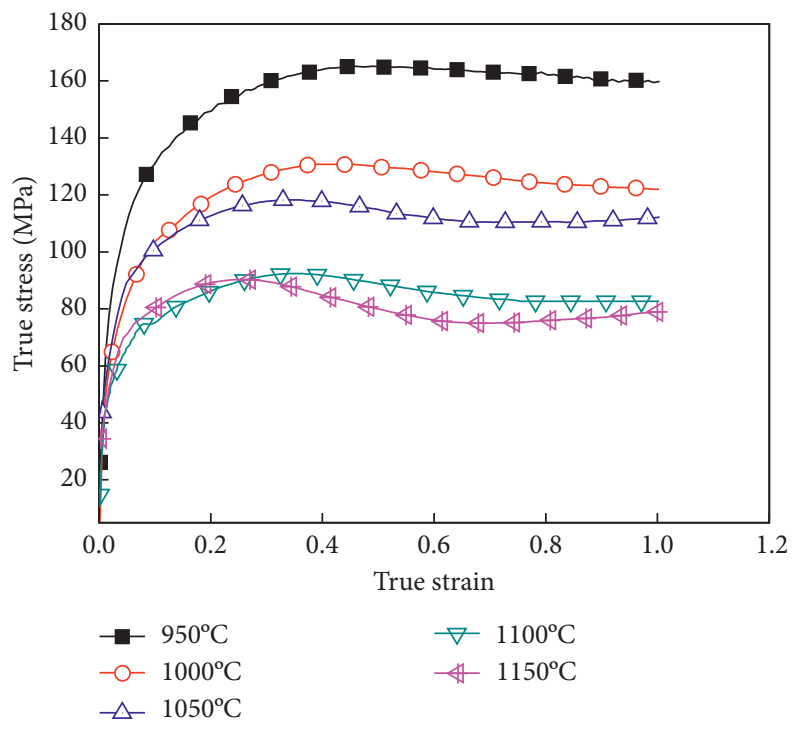

(c)

Figure 2: True stress-true strain curves of $\# 2$ sample under different temperatures and strain rates. (a) $0.1 \mathrm{~s}^{-1}$; (b) $0.5 \mathrm{~s}^{-1}$; (c) $1 \mathrm{~s}^{-1}$.

$$
\begin{aligned}
& \ln \dot{\varepsilon}+\frac{Q}{\mathrm{RT}}=\ln A_{1}+n^{\prime} \ln \sigma, \\
& \ln \dot{\varepsilon}+\frac{Q}{\mathrm{RT}}=\ln A_{2}+\beta \sigma .
\end{aligned}
$$

The slopes of the plots of $\ln \dot{\varepsilon}-\ln \sigma$ and $\ln \dot{\varepsilon}-\sigma$ of \#1 sample can be used for obtaining the values of $n^{\prime}$ and $\beta$, respectively, as shown in Figures 4(a) and 4(b). And the values of $n^{\prime}, \beta$, and $\alpha$ of \#1 sample are 5.9203, $0.0632 \mathrm{MPa}^{-1}$, and $0.0107 \mathrm{MPa}^{-1}$, respectively. Taking natural logarithm of both sides of (1), then the following formula is obtained:

$$
\ln \dot{\varepsilon}=\ln A+n \ln \sinh (\alpha \sigma)+\left(\frac{-Q}{\mathrm{RT}}\right) .
$$

With the temperature unchanged, the plot of $\ln \dot{\varepsilon}-\ln \sinh (\alpha \sigma)$ of \#1 sample under different deformation temperatures is shown in Figure 4(c). The mean slop and intercept of the plot can be used to calculate the values of $n$ and $\ln A$, respectively [19]. And the values of $n$ and $\ln A$ of \#1 sample are 5.06 and 26.80 , respectively. So the value of $A$ is $4.37 \times 10^{11}$.

Similarly, at a certain strain rate, the relation between $\ln \sinh (\alpha \sigma)$ and 1000/T can be obtained with the assistance 


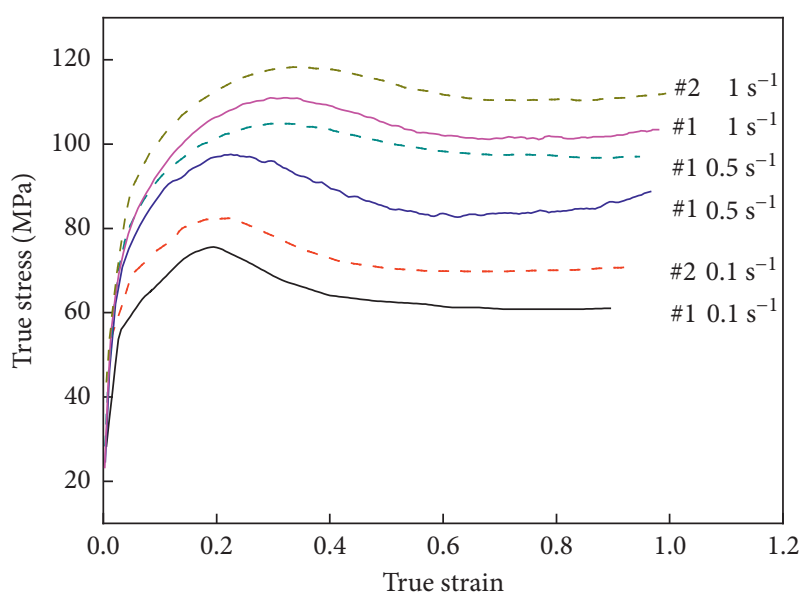

FIgURE 3: True stress-true strain curves of \#1 and \#2 samples under different strain rates and a constant temperature of $1050^{\circ} \mathrm{C}$.

of peak stress and temperature, as shown in Figure 4(d). A linear relationship is recognizable, and the slop of the line is $Q / R n$. And the deformation activation energy $Q$ of \#1 sample is obtained as $305.83 \mathrm{~kJ} / \mathrm{mol}$. Using the same method, the values of $n, A$, and $Q$ of \#2 sample are obtained as 4.73, $2.04 \times 10^{11}$, and $348.38 \mathrm{~kJ} / \mathrm{mol}$, respectively. And then, the hot working equations can be expressed as follows:

$$
\begin{aligned}
& \dot{\varepsilon}=4.37 \times 10^{11} \cdot[\sinh (0.0107 \sigma)]^{5.06} \exp \left[\frac{-305830}{\mathrm{RT}}\right](\# 1), \\
& \dot{\varepsilon}=2.04 \times 10^{11} \cdot[\sinh (0.0147 \sigma)]^{4.73} \exp \left[\frac{-348380}{\mathrm{RT}}\right](\# 2) .
\end{aligned}
$$

Also, the Zener-Hollomon parameter of \#1 and \#2 samples can be represented as follows:

$$
\begin{aligned}
& Z=\dot{\varepsilon} \exp \left(\frac{305830}{\mathrm{RT}}\right)=4.37 \times 10^{11}(\sinh (0.0107 \sigma))^{5.06}(\# 1), \\
& Z=\dot{\varepsilon} \exp \left(\frac{348380}{\mathrm{RT}}\right)=2.04 \times 10^{11}(\sinh (0.0147 \sigma))^{4.73}(\# 2) .
\end{aligned}
$$

The formation and growth of recrystallized nucleus requires the diffusion of atoms. When the metal is heated to a certain temperature, the atoms are activated and start to migrate, so that the crystallization process could be proceeded.

Generally, the thermal activation is a critical factor affecting the hot deformability during the hot deformation. The smaller the value of activation energy, the lower the barrier of dislocation and phase boundary/grain boundary migration is and the larger the tendency of dynamic recrystallization during the deformation is. On the basis of experimental data and constitutive equation, obviously it can be easily found that the increment of the hot deformation activation energy is $43 \mathrm{~kJ} / \mathrm{mol}$ due to adding rare earth. Therefore, high deformation temperature is needed for dynamic recrystallization of \#2 sample. Based on the above experimental results, it can be deduced that the occurrence of dynamic recrystallization is delayed by adding a small amount of rare earth in the as-cast $30 \mathrm{Mn}$ steel.

3.3. Dynamic Recrystallization Volume Fraction. In order to establish the relationship between the deformation parameters and dynamic recrystallization volume fraction, the Johnson-Mehl-Avrami (JMA) equation [20] is usually rewritten as

$$
f_{\text {dyn }}=1-\exp \left(-b(Z) t^{n(Z)}\right)
$$

where $f_{\text {dyn }}$ is the dynamic recrystallization volume fraction, $b(Z)$ and $n(Z)$ are, respectively, the functions of the deformation parameter $Z$.

Assuming that the critical strain corresponds to the recrystallization volume fraction of $0.5 \%$, and the steadystate strain corresponds to the recrystallization volume fraction of $99 \%,(10)$ can be rewritten as

$$
\begin{aligned}
& f_{\text {dyn }}=0.005=1-\exp \left(-b(Z) t_{\mathrm{c}}^{n(Z)}\right), \\
& f_{\text {dyn }}=0.99=1-\exp \left(-b(Z) t_{\mathrm{s}}^{n(Z)}\right) .
\end{aligned}
$$

From the above two formulas, (12) can be obtained:

$$
\begin{aligned}
& n(Z)=\frac{\ln [\ln (1-0.005) / \ln (1-0.99)]}{\ln t_{\mathrm{c}} / t_{\mathrm{s}}}, \\
& b(Z)=-\frac{\ln (1-0.005)}{t_{\mathrm{c}}^{n(Z)}},
\end{aligned}
$$

where $t_{\mathrm{c}}=\varepsilon_{\mathrm{c}} / \dot{\mathcal{\varepsilon}}, t_{\mathrm{s}}=\varepsilon_{\mathrm{s}} / \dot{\mathcal{\varepsilon}}, \varepsilon_{\mathrm{c}}$ is the critical strain for DRX, and $\varepsilon_{\mathrm{s}}$ is the steady-state strain.

On the basis of experimental data, the values of the $b(Z)$ and $n(Z)$ under different deformation conditions can be obtained. And then, these values are substituted into (10), and the dynamic recrystallization volume fraction is obtained.

When the strain rate is constant, the volume fraction of dynamic recrystallization usually can be expressed as follows [21]:

$$
X=1-\exp \left[k\left(\frac{\varepsilon-\varepsilon_{\mathrm{c}}}{\varepsilon_{\mathrm{p}}}\right)^{m}\right] \quad\left(\varepsilon \geq \varepsilon_{\mathrm{c}}\right),
$$

where $X$ is the dynamic recrystallization volume fraction, $k$ and $m$ are the dynamic recrystallization parameters depending on chemical composition and hot deformation conditions, and $\varepsilon$ and $\varepsilon_{\mathrm{p}}$ are the true strain and the peak strain, respectively.

Taking natural logarithms of both sides of (13) two times, the corresponding formula can be obtained:

$$
\ln [-\ln (1-X)]=m \ln \left(\frac{\varepsilon-\varepsilon_{\mathrm{c}}}{\varepsilon_{\mathrm{p}}}\right)+\ln (-k)
$$

With the assistance of the experimental data, the values of $k$ and $m$ can be determined by using nonlinear regression. These values are substituted into (13), and then the dynamic 


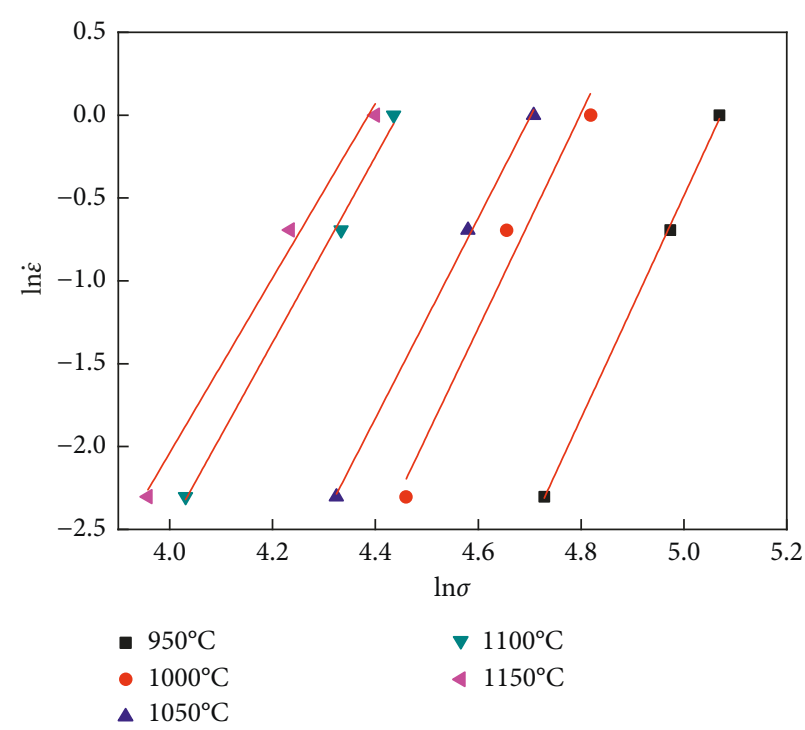

(a)

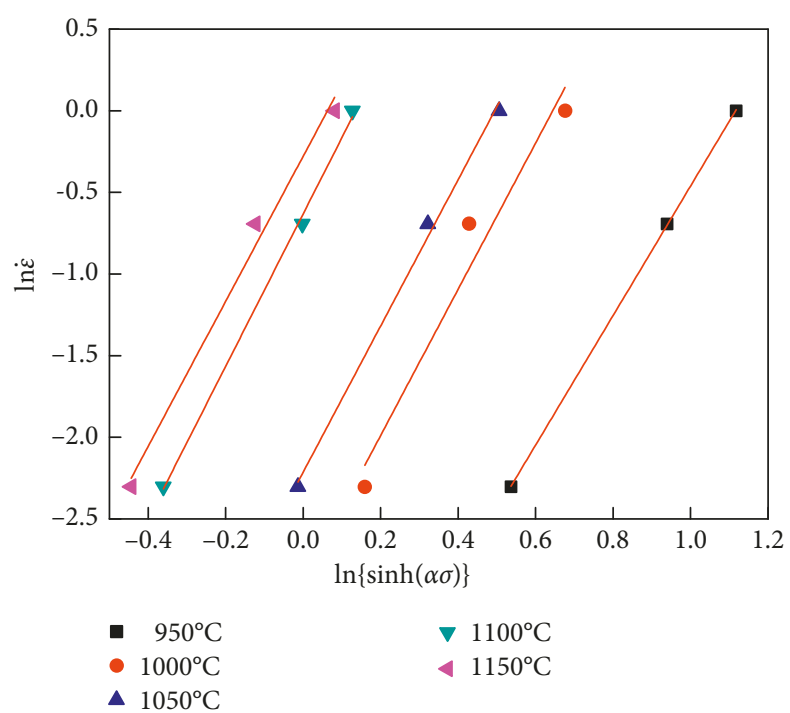

(c)

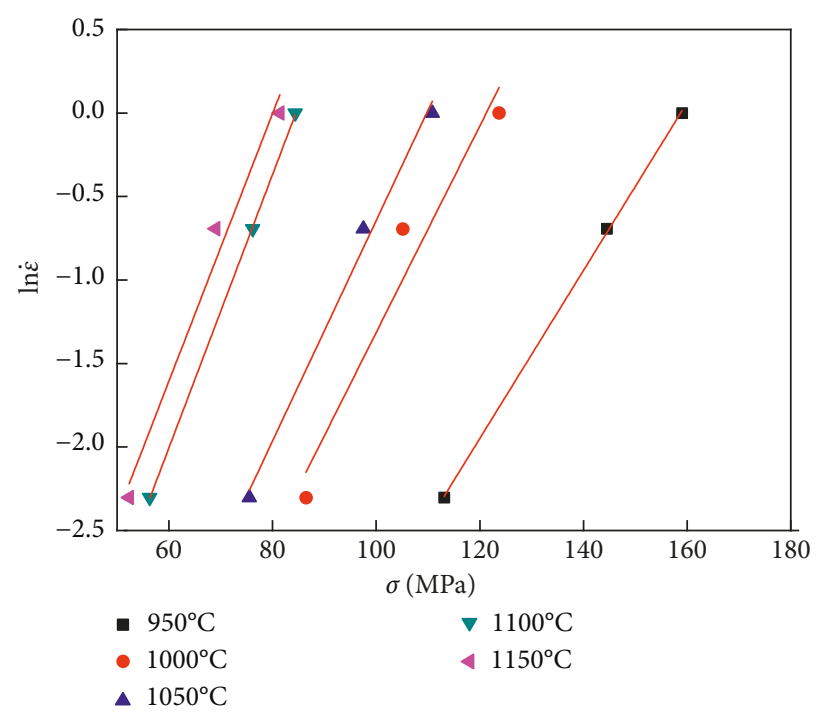

(b)

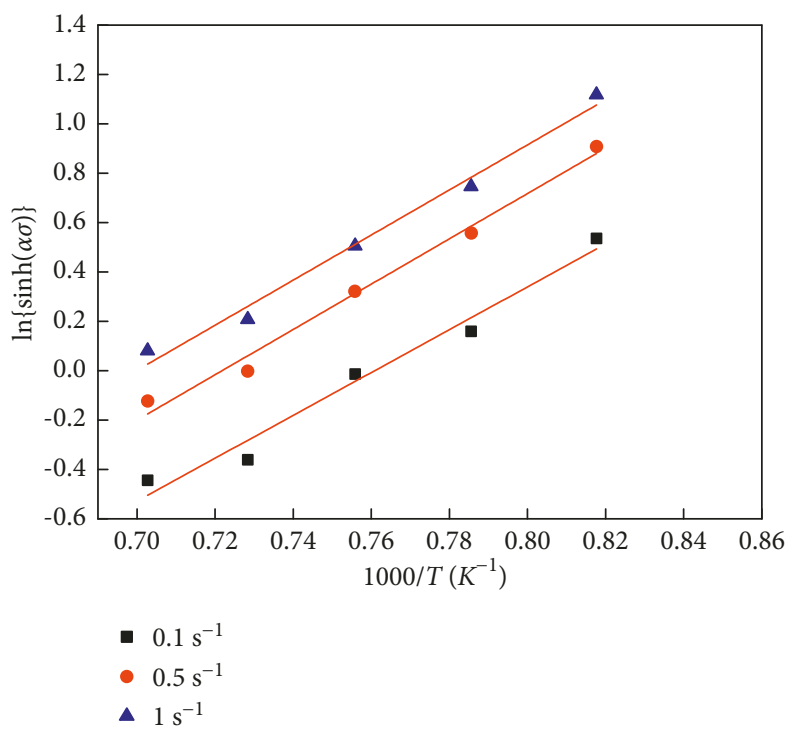

(d)

Figure 4: Plots of $\ln \dot{\varepsilon}-\ln \sigma$ (a), $\ln \dot{\varepsilon}-\sigma$ (b), $\ln \dot{\varepsilon}-\ln \sinh \alpha \sigma$ (c), and $\ln \sinh \alpha \sigma-1000 / T$ (d) of \#1 sample.

recrystallization kinetics models of $\# 1$ and $\# 2$ samples are as follows:

$$
\begin{aligned}
& X=1-\exp \left[-1.36\left(\frac{\varepsilon-\varepsilon_{\mathrm{c}}}{\varepsilon_{\mathrm{p}}}\right)^{2.41}\right](\# 1), \\
& X=1-\exp \left[-0.84\left(\frac{\varepsilon-\varepsilon_{\mathrm{c}}}{\varepsilon_{\mathrm{p}}}\right)^{2.28}\right](\# 2) .
\end{aligned}
$$

From the dynamic recrystallization kinetic equations, it is easily seen that the values of $k$ and $m$ of \#1 sample are larger than that of \#2 sample. That is to say, under the same deformation conditions, the dynamic recrystallization volume fraction of \#1 sample is larger than that of \#2 sample. In other words, rare earth addition impedes the process of dynamic recrystallization of the as-cast $30 \mathrm{Mn}$ steel.

In order to understand the effect rare earth addition on the dynamic recrystallization process, the dynamic recrystallization volume fraction curves of \#1 and \#2 samples are given in Figure 5. The deformation temperature is $1050^{\circ} \mathrm{C}$, and the strain rates are $0.1,0.5$, and $1 \mathrm{~s}^{-1}$, respectively.

As can be seen from Figure 5 under the same deformation conditions, dynamic recrystallization kinetics curves of tendency of \#1 and \#2 sample are basically the same. On one hand, it can be seen that all the characteristic curves are in sigmoidal manner with respect to time, which indicates that the dynamic recrystallization volume fraction increases with the strain increasing, remarkably in the middle and then slowly near the end of deformation [22]. On 


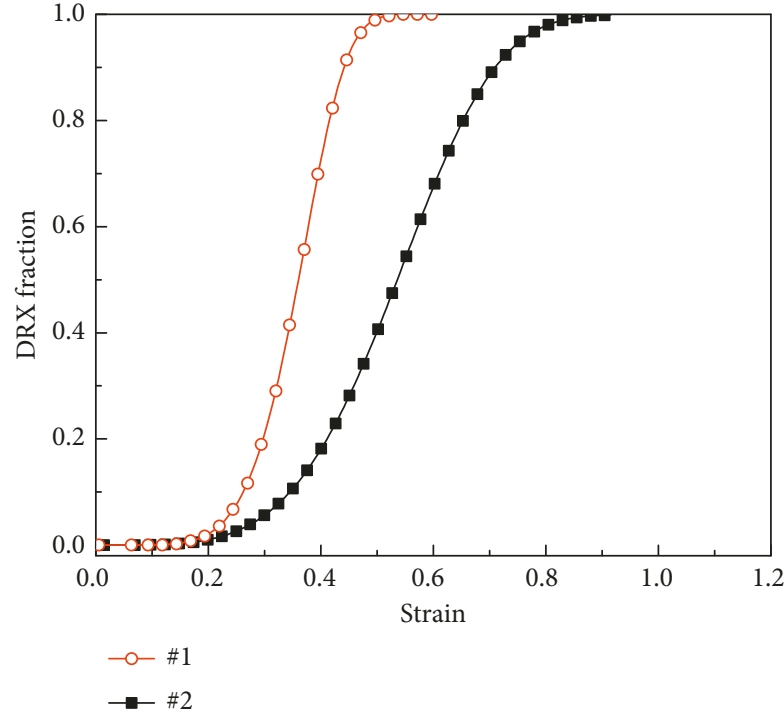

(a)

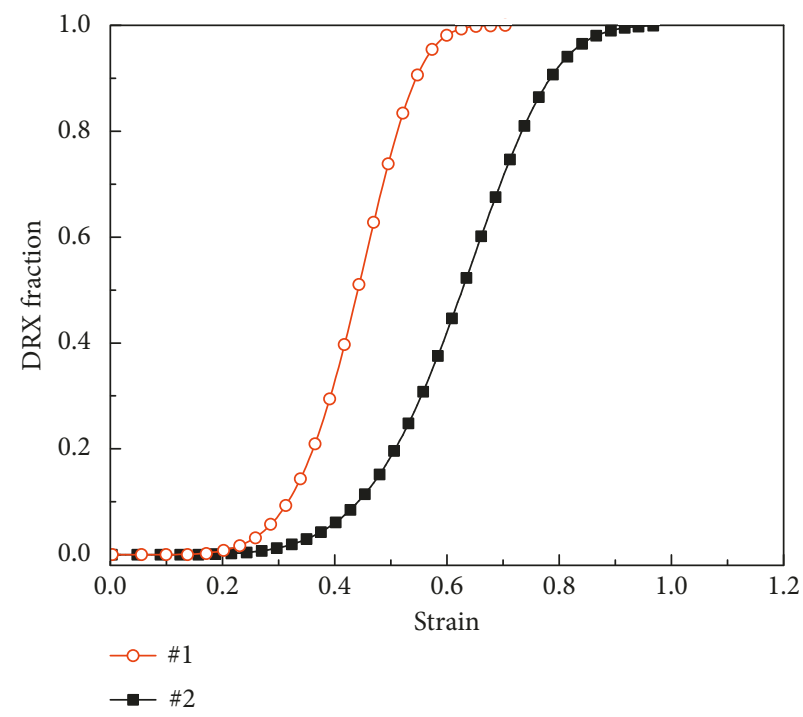

(b)

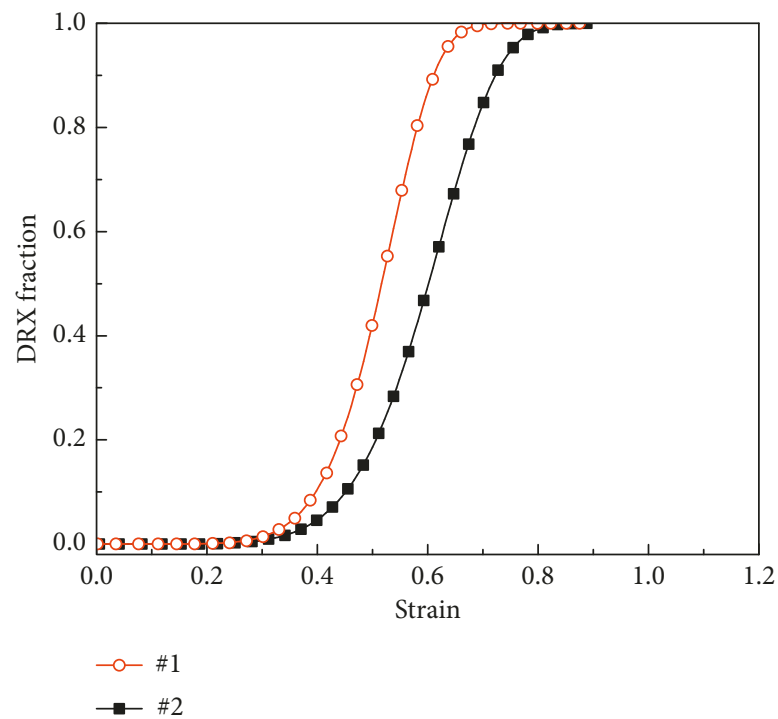

(c)

Figure 5: Dynamic recrystallization volume fraction curves under various strain rates and a constant temperature $\left(1050^{\circ} \mathrm{C}\right)$ of $\# 1$ and $\# 2$ samples. (a) $\dot{\varepsilon}=0.1 \mathrm{~s}^{-1}$; (b) $\dot{\varepsilon}=0.5 \mathrm{~s}^{-1}$; (c) $\dot{\varepsilon}=1 \mathrm{~s}^{-1}$.

the other hand, for \#1 and \#2 samples, when the temperature is constant, the increase of strain rate results in the increase of the strain required for the same DRX volume fraction, which indicates that DRX is delayed with the increase of strain rate.

In addition, it is found that the strain of \#1 sample is smaller than that of \#2 sample under the same dynamic recrystallization volume fraction. For example, when the strain rate is $0.1 \mathrm{~s}^{-1}$ and the dynamic recrystallization volume fraction reaches $20 \%$, the strain rates of \#1 and \#2 samples are, respectively, 0.2 and 0.3 . On the other side, when the deformation temperature is $1050^{\circ} \mathrm{C}$ and the dynamic recrystallization volume fraction almost approaches $100 \%$, the strain rates of $\# 1$ and $\# 2$ samples are
0.52 and 0.86 , respectively. All the results indicate that the rare earth additions could inhibit dynamic recrystallization behavior.

3.4. Hot Deformation Microstructures. The deformation microstructures of \#1 and \#2 samples are shown in Figure 6; here the strain rate is $0.5 \mathrm{~s}^{-1}$ and the deformation temperatures are $950^{\circ} \mathrm{C}, 1050^{\circ} \mathrm{C}$, and $1150^{\circ} \mathrm{C}$, respectively. It can be seen that the average grain size increases with the increase of deformation temperature. The reason is that higher temperature results in a higher driving force for grain growth. The same phenomena were also reported in other research works [23]. 


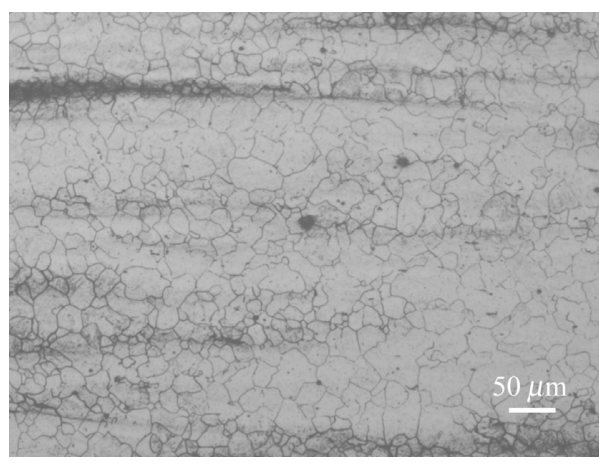

(a)

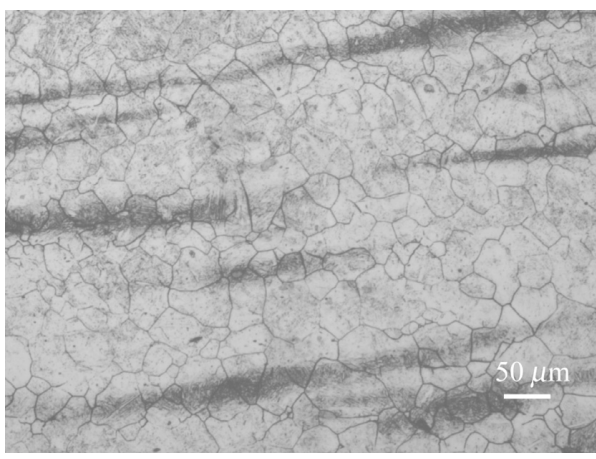

(c)

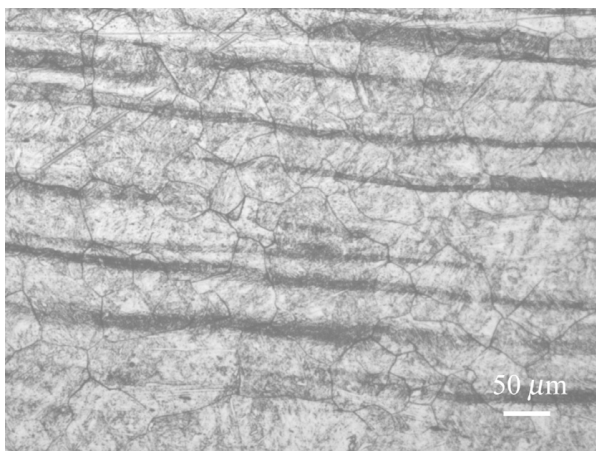

(e)

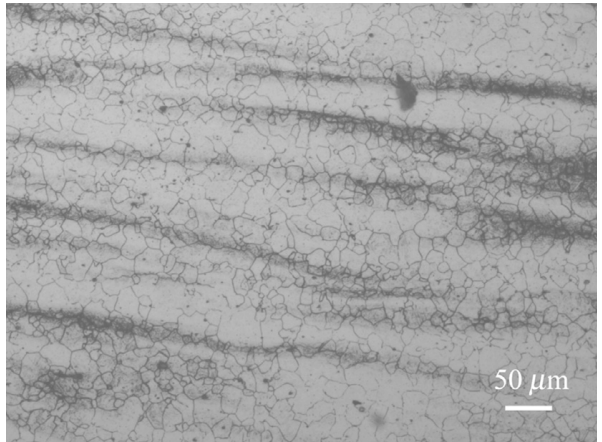

(b)

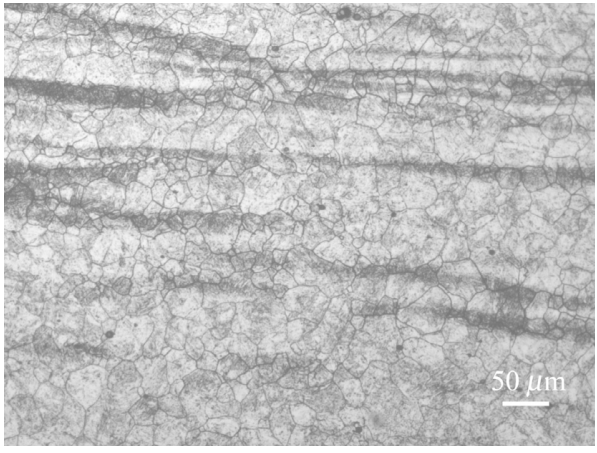

(d)

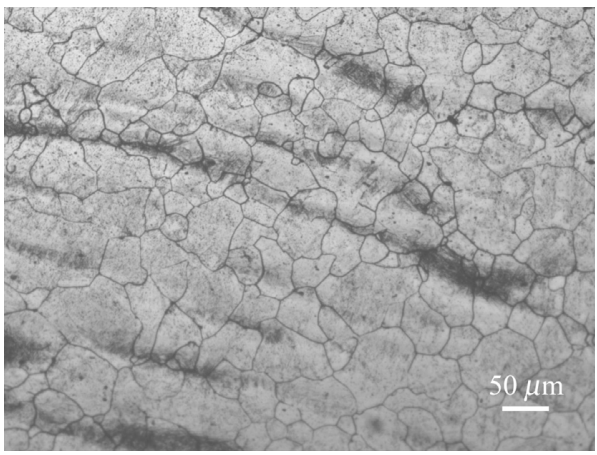

(f)

Figure 6: Hot deformed microstructures of \#1 and \#2 samples under a constant strain rate $\left(0.5 \mathrm{~s}^{-1}\right)$ and different deformation temperatures. (a) $\# 1$ and (b) $\# 2$ at $950^{\circ} \mathrm{C}$; (c) $\# 1$ and (d) $\# 2$ at $1050^{\circ} \mathrm{C}$; (e) $\# 1$ and (f) $\# 2$ at $1150^{\circ} \mathrm{C}$.

In addition, the grain size of $\# 2$ sample is much finer than that of \#1 sample. Especially when the strain rate is $0.5 \mathrm{~s}^{-1}$ and the temperature is $1050^{\circ} \mathrm{C}$, the mean DRX grain sizes of \#1 sample and \#2 sample are about $42 \mu \mathrm{m}$ and $34 \mu \mathrm{m}$, respectively, although the dynamic recrystallization has taken place in the both samples and many crystalline grains in local region begin to grow up, as shown in Figures 6(c) and $6(\mathrm{~d})$.

Because rare earth atoms are much larger than iron atoms, rare earth atoms would incline to gather in the grain boundaries. As a result, the grain boundaries migrations are hindered, and then, the growing rate of crystal nucleus is reduced during the dynamic recrystallization. Similar results
[24] were reported that the segregation of rare earth atoms along grain boundaries could reduce the boundary energy and driving force of grain growth, and then the growth tendency of austenite grains can be restrained. Therefore, the hot deformed microstructure can be refined by adding rare earth elements.

\section{Conclusions}

The effect of rare earth on dynamic recrystallization behavior of as-cast $30 \mathrm{Mn}$ steel was investigated at the temperature range from $950^{\circ} \mathrm{C}$ to $1150^{\circ} \mathrm{C}$ and strain rate range from $0.1 \mathrm{~s}^{-1}$ to $1 \mathrm{~s}^{-1}$. Constitutive equations were derived and the 
Zenner-Hollomon parameters were establised using the flow stress data at a true strain of 0.9. The activation energy, hot working equation, and DRX kinetics model of the as-cast $30 \mathrm{Mn}$ steel were obtained. The following conclusions are derived from this study:

(1) The true stress-strain curves show that the higher the deformation temperature or lower strain rate, the easier the dynamic recrystallization occurrence is in the two tested steels.

(2) For as-cast 30Mn steel, rare earth addition can lead to an increase of the hot deformation activation energy, retard dynamic recrystallization behavior, and refine the microstructures after hot deformation.

\section{Conflicts of Interest}

The authors declare that they have no conflicts of interest.

\section{Acknowledgments}

This work was supported by the National Natural Science Foundation of China (Grant no. 51405325), the Fund for Shanxi "1331 Project" Key Subjects Construction, a Ph.D. research startup foundation of Taiyuan University of Science and Technology (Grant no. 20162024), and the National Natural Science Foundation of Shanxi, China (Grant no. 201701D121069).

\section{References}

[1] J. F. Li, Report of Wind-energy Development in China, China Environmental Science Press, Beijing, China, 2011.

[2] Y. T. Li, L. Ju, H. P. Qi, F. Zhang, and G. Z. Chen, "Technology and experiments of $42 \mathrm{CrMo}$ bearing ring forming based on casting ring blank," Chinese Journal of Mechanical Engineering, vol. 27, no. 2, pp. 418-427, 2013.

[3] H. Mirzadeh, J. M. Cabrera, J. M. Prado, and A. Najafizadeh, "Hot deformation behavior of a medium carbon microalloyed steel," Materials Science and Engineering: A, vol. 528, no. 10-11, pp. 3876-3882, 2011.

[4] H. Mirzadeh and A. Najafizadeh, "Prediction of the critical conditions for initiation of dynamic recrystallization," Materials \& Design, vol. 31, no. 3, pp. 1174-1179, 2010.

[5] F. C. Ren, F. Chen, and J. Chen, "Investigation on dynamic recrystallization behavior of martensitic stainless steel," Advances in Materials Science and Engineering, vol. 2014, Article ID 986928, 16 pages, 2014.

[6] L. M. Wang, Q. Lin, J. W. Ji, and D. N. Lan, "New study concerning development of application of rare earth metals in steels," Journal of Alloys and Compounds, vol. 408-412, pp. 384-386, 2006.

[7] H. Mirzadeh and A. Najafizadeh, "The rate of dynamic recrystallization in 17-4 PH stainless steel," Materials \& Design, vol. 31, no. 10, pp. 4577-4583, 2010.

[8] B. C. Zhao, T. Zhao, G. Y. Li, and Q. Lu, "The kinetics of dynamic recrystallization of a low carbon vanadium-nitride microalloyed steel," Materials Science and Engineering: A, vol. 604, pp. 117-121, 2014.

[9] J. M. Cabrera, I. Mejía, and J. M. Prado, "Effect of rare-earth metals on the hot strength of HSLA steels," Zeitschrift für Metallkunde, vol. 93, pp. 1132-1139, 2002.
[10] L. y. Lan, C. 1. Qiu, D. w. Zhao, X.-h. Gao, and L.-x. Du, "Behavior of low carbon high niobium microalloyed steel," Journal of Iron and Steel Research, International, vol. 18, no. 1, pp. 55-60, 2011.

[11] X. r. Lei, Q. f. Ding, Y. y. Chen, X. 1. Rui, S. r. Li, and Q.-f. Wang, "Effect of niobium on dynamic recrystallization behavior of 5\% Ni steel," Journal of Iron and Steel Research, International, vol. 20, no. 6, pp. 38-44, 2013.

[12] D. Mclean and R. J. Northeott, "Micro-examination and electrode-potential measurement of temper-brittle steels," JISI International, vol. 158, pp. 169-177, 1948.

[13] C. J. Liu, H. L. Liu, and M. F. Jiang, "Effect of rare earth elements on transformation behavior and microstructure characteristics in X80 pipeline steel," Rare Metal Materials and Engineering, vol. 40, pp. 51-55, 2011.

[14] N. Stanford, M. D. Callaghan, and B. De Jong, "The effect of rare earth elements on the behavior of magnesium-based alloys: part 1-hot deformation behavior," Materials Science and Engineering: A, vol. 565, pp. 459-468, 2013.

[15] Q. Lin, F. Guo, and X. Y. Zhu, "Behaviors of lanthanum and cerium on grain boundaries in carbon manganese clean steel," Journal of Rare Earths, vol. 25, no. 4, pp. 485-489, 2007.

[16] F. Garofalo, "An empirical relation defining the stress dependence of minimum creep rate in metal," Transactions of the Metallurgical Society of AIME, vol. 227, pp. 3351-3356, 1963.

[17] C. M. Sellars and W. M. Tegart, "On the mechanism of hot deformation," Acta Metallurgica, vol. 14, no. 9, pp. 1136-1138, 1966.

[18] C. Zener and J. H. Hollomon, "Effect of strain upon plastic flow of steel," Journal of Applied Physics, vol. 15, no. 1, pp. 22-32, 1944.

[19] H. J. McQueen and N. D. Ryan, "Constitutive analysis in hot working," Materials Science and Engineering: A, vol. 322, no. 1-2, pp. 43-63, 2002.

[20] J. W. Christian, The Theory of Transformations in Metals and Alloys, Pergamon Press, Oxford, UK, 1965.

[21] L. X. Kong, P. D. Hodgson, and B. Wang, "Development of constitutive models for metal forming with cyclic strain softening," Journal of Materials Processing Technology, vol. 89-90, pp. 44-50, 1999.

[22] M. Shaban and B. Engbali, "Determination of critical conditions for dynamic recrystallization of a microalloyed steel," Materials Science and Engineering: A, vol. 527, no. 16-17, pp. 4320-4325, 2010.

[23] S. L. Zhu, H. Z. Cao, J. S. Ye, W. H. Hu, and G. Q. Zheng, "Dynamic recrystallization behavior of medium carbon Cr-Ni-Mo-Nb steel during hot deformation," Journal of Iron and Steel Research, International, vol. 22, no. 3, pp. 264-271, 2015.

[24] Q. X. Yang, A. R. Wang, M. Gao, H. Q. Wu, and T. B. Guo, "Effect of rare earth elements on austenite growth dynamics of steel 9 $\mathrm{Cr}_{2} \mathrm{Mo}$," Journal of Iron and Steel Research, International, vol. 3, pp. 43-45, 1996. 


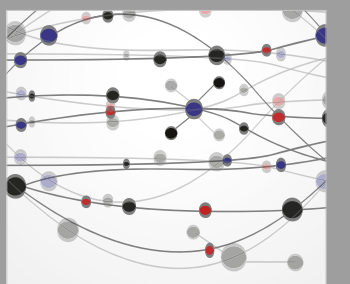

The Scientific World Journal
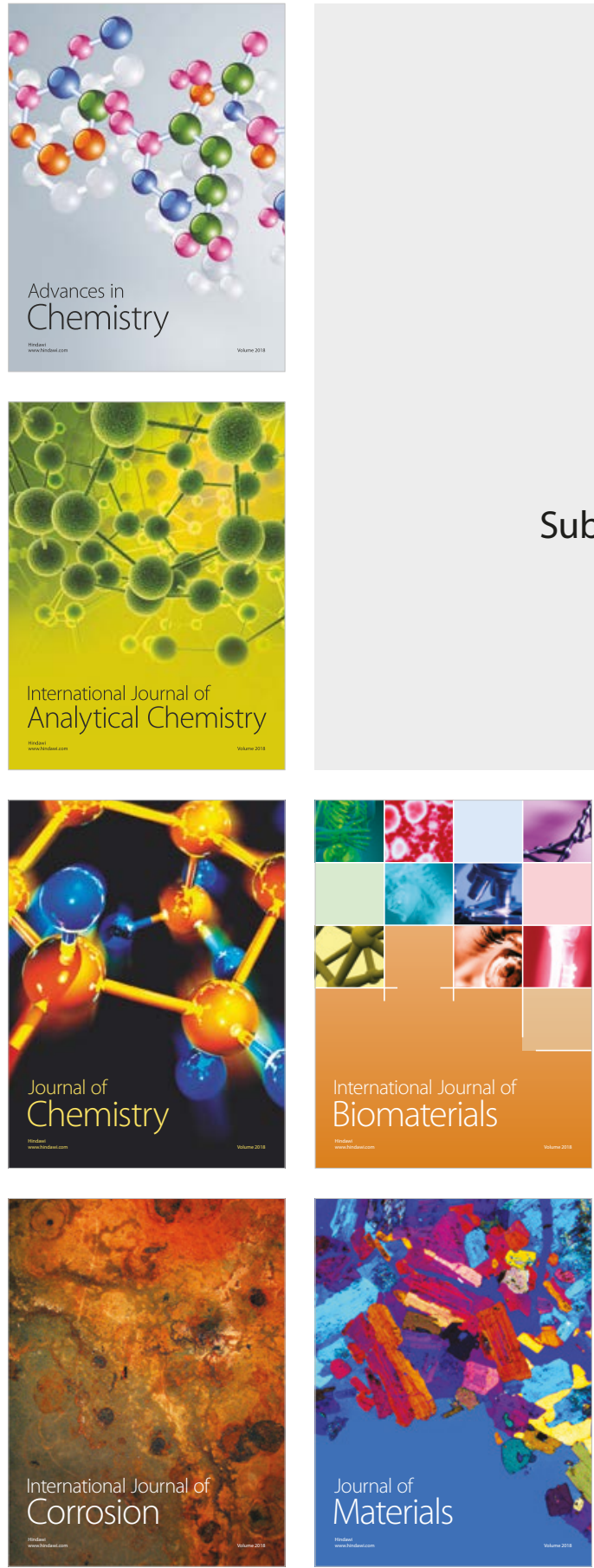

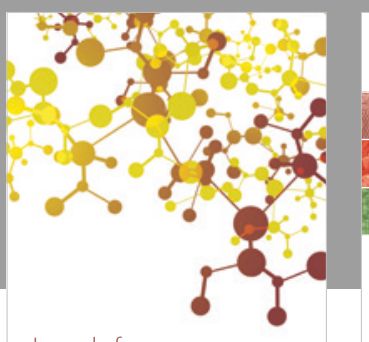

Journal of

Applied Chemistry
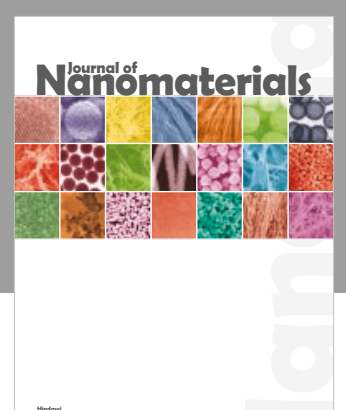

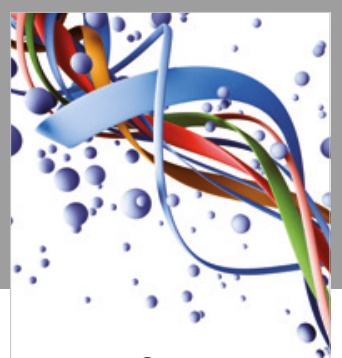

Scientifica

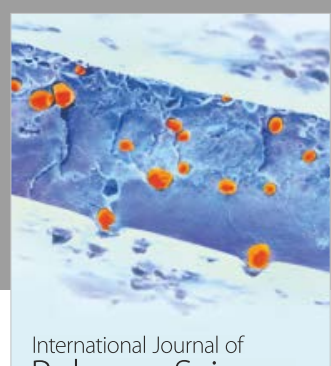

Polymer Science

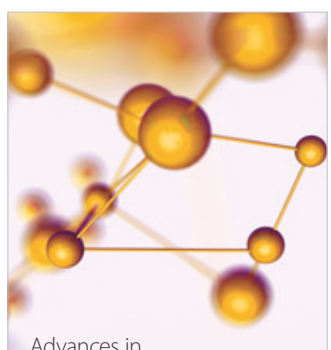

Physical Chemistry
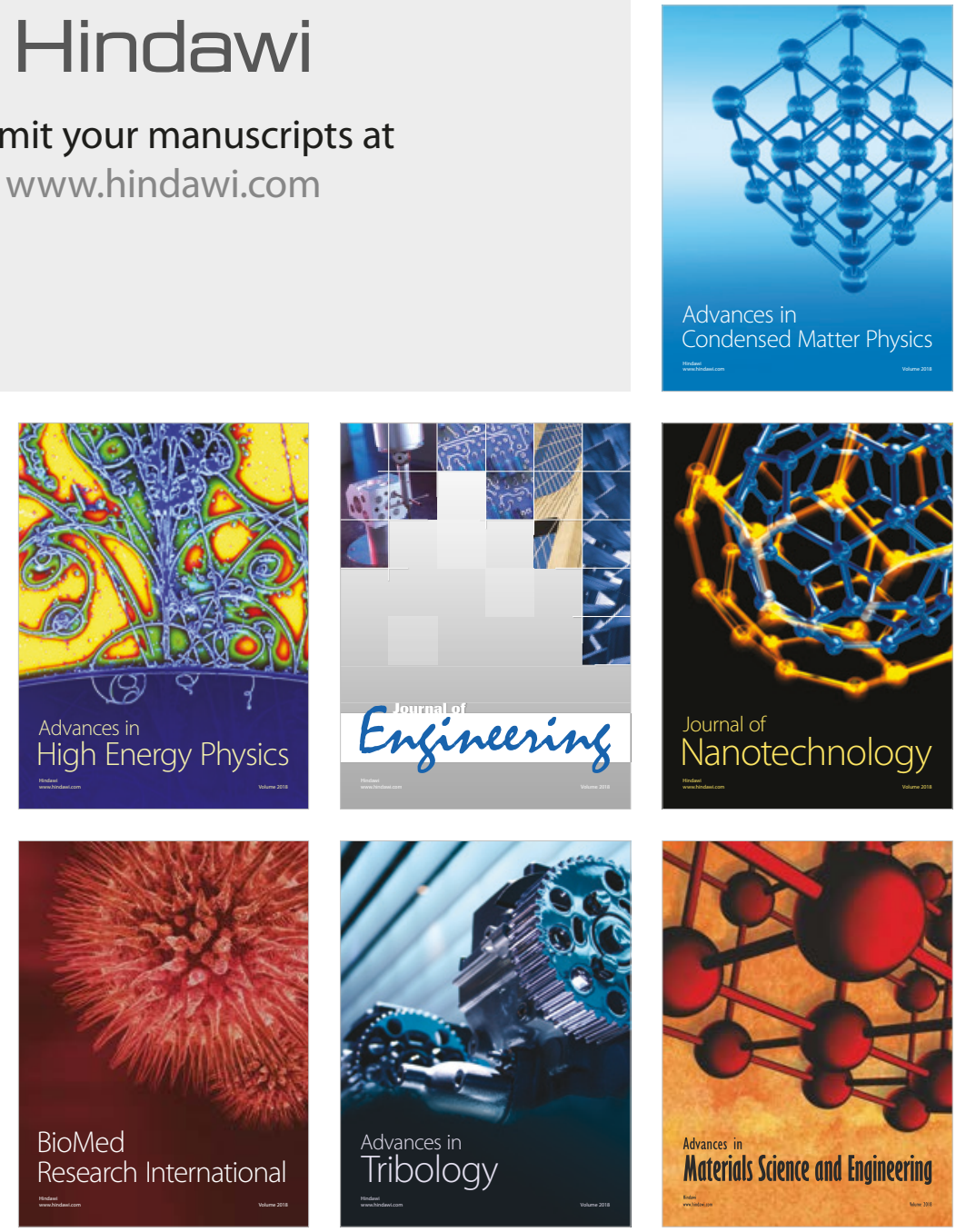